\title{
The Influence of Reading Attitudes on Reading Strategies of University Students through the Motives of Reading
}

\author{
EunJoo Kim \\ Faculty of Liberal Arts, Eulji University, Seongnam, Korea \\ kej70@eulji.ac.kr
}

\begin{abstract}
This study analyzes the structural relationship between the reading attitude and the reading motivation that influences the reading strategy of selected university students. The data used in this research were gathered from a survey conducted among 600 students at E University in Gyeonggi-do. These data were examined to confirm the relationship between variables and their multicollinearity, revealing a high interrelationship between the independent variables. Using the relative convergence index (NFI, IFI, TLI, CFI) in comparison to the absolute convergence index (RMSEA), the study has evaluated how well the theoretical model fits the data as well as it has identified the worst independent model. The results showed that first, there is a static correlation between reading attitudes, reading strategies, and reading motivation variables; second, the reading strategy of university students showed that the motivation for reading directly has a higher influence on the reading strategy than the attitude of university students with a motive for reading. Therefore, the importance and awareness of university students' motivation for reading are raised, and further research is needed on the development of
\end{abstract}

\section{EunJoo Kim}

Faculty of Liberal Arts, Eulji University, Seongnam, Korea kej70@eulji.ac.kr various programs that improve and support the reading environment in universities.

Keywords : University Student, Reading Motives, Strategies, Attitudes

\section{Introduction}

The advent of the fourth industrial revolution paved the way for vast accessibility and production of knowledge and information. However, if you do not have the motivation to read this valuable knowledge and information and make it your own, make it your own, that is useless. You need to have a clear objective to attain the knowledge desired. Reading is highly recommended in universities to cultivate culture. It enables the creation of new knowledge through critical thinking, exploration, and knowledge acquisition.

The average number of books read annually by people aged 13 and older as recorded by the National Statistical Office was 10.8 in 2009, 12.8 in 2011, 11.2 in 2013, 9.3 in 2015, and 9.5 in 2017. According to Bill Gates, "What is more important than a Harvard diploma is the habit of reading" In colleges, reading is the basic method for learning and the typical knowledge activity towards the development of thought through writing. It is an act of social participation and cultural creation [1]. In other words, reading is the basic act of cultivating thinking power and culture and creating new knowledge. 
Reading at university is an activity that allows students to understand rapidly changing social situations through intellectual reflection and to actively recognize social problems. Learning in college requires a reading strategy in the process of reconstructing meaning by adding new knowledge to the existing knowledge that one has. Reading strategies are also possible through the reconstruction of the meaning of knowledge and deep thinking. These reading strategies are one way to effectively study in college.

According to Charles (1996) and Wood (1992), college students can use books according to their needs as mature readers and judge for themselves what to read [2]. Wood (1992) was able to find the reference materials needed for university assignments in functional literacy with which college students can read and write [3]. Reading for appreciation and reading for learning are different from each other [4]. Many college students tend not to prefer reading as they are accustomed to using the Internet and the Social Network Service (SNS). If they do not have the motivation and right attitude to read, it is difficult to use a reading strategy, which is the ability to read books.

The motivations for reading are relevant to learners' reading attitudes, consistency in reading performance, reading efficacy, etc., and allow learners to perform and sustain their performance [1]. Reading attitudes are analyzed as cognitive, affective, and behavioral factors. First, reading attitudes as cognitive factors represent beliefs or opinions about reading. Second, reading attitudes as defining elements represent feelings or assessments of reading. Lastly, reading attitudes as behavioral factors indicate practical reading behavior and reading intent $[5,6]$.

Logan (2011), who studied children on reading motivations, confirmed that reading motivations are a predictive growth factor for reading strategies, in addition to cognitive abilities [7]. A study by McGeown et al (2015) showed that reading strategies and reading attitudes, confidence, and performance are correlated [8]. In their study of university students' reading attitudes and strategies, Hong (2006) determined that university students should be able to select and utilize books for various purposes based on knowledge already acquired, and strategically select and read books as needed [9].

Most of the preceding research related to university students' motivation for reading has been centered on primary and secondary school students. Further, most of the preceding research conducted on university students analyzed one-dimensional relationships between reading motivations, reading attitudes and reading strategy factors, and analysis of multidimensional relationships among the three factors is insufficient. Thus, the structural relationship between the three factors is analyzed in this study, and the study of the effect of the reading attitude of university students on reading strategy is meaningful.

\section{Research method}

\subsection{Study Subjects}

This study was conducted among 600 people from May 1, 2019, to June 31, 2019. Excluding the answers with high missing values, a total of 505 responses were analyzed. The general characteristics of the study subjects are shown in Table 1.

Table 1: General characteristic $(\mathbf{N}=\mathbf{5 0 5})$

\begin{tabular}{|c|c|c|c|}
\hline & Observational variable & $\begin{array}{l}\text { Frequ } \\
\text { ency }\end{array}$ & $\%$ \\
\hline \multirow{2}{*}{ Gender } & Male & 152 & 30.1 \\
\hline & Female & 353 & 69.9 \\
\hline \multirow{3}{*}{ College } & \multirow{3}{*}{$\begin{array}{l}\text { College of Nursi ng } \\
\text { College of Health Science } \\
\text { College of Health Industry }\end{array}$} & 33 & 6.5 \\
\hline & & 239 & 47.3 \\
\hline & & 233 & 46.1 \\
\hline \multirow{15}{*}{ Major } & Department of Nursing & 33 & 6.5 \\
\hline & Optics department & 48 & 9.5 \\
\hline & $\begin{array}{l}\text { Department of Medical } \\
\text { Engineering }\end{array}$ & 17 & 3.4 \\
\hline & $\begin{array}{l}\text { Department of Clinical } \\
\text { Pathology }\end{array}$ & 37 & 7.3 \\
\hline & Department of physica 1 therapy & 26 & 5.1 \\
\hline & Department of Radiology & 29 & 5.7 \\
\hline & $\begin{array}{c}\text { Department of Emergency } \\
\text { Rescue }\end{array}$ & 33 & 6.5 \\
\hline & Department of Dental Hygiene & 31 & 6.1 \\
\hline & Department of Skin Care & 20 & 4.0 \\
\hline & Department of Medical IT & 31 & 6.1 \\
\hline & Department of Funeral Guidance & 22 & 4.4 \\
\hline & $\begin{array}{l}\text { Department of Food Industry and } \\
\text { Food and Rural Affairs }\end{array}$ & 52 & 10.3 \\
\hline & $\begin{array}{c}\text { Department of Food and } \\
\text { Nutrition }\end{array}$ & 12 & 2.4 \\
\hline & Department of infant education & 17 & 3.4 \\
\hline & $\begin{array}{l}\text { Department of Medical } \\
\text { Management }\end{array}$ & 14 & 2.8 \\
\hline
\end{tabular}




\begin{tabular}{|c|c|c|}
\hline $\begin{array}{l}\text { Department of Medical Publicity } \\
\text { and Design }\end{array}$ & 19 & 3.8 \\
\hline $\begin{array}{r}\text { Department of Addiction } \\
\text { Rehabilit ation and Welfare }\end{array}$ & 15 & 3.0 \\
\hline $\begin{array}{l}\text { Department of Health and } \\
\text { Environmental Safety }\end{array}$ & 29 & 5.7 \\
\hline Department of Sports Outdoors & 20 & 4.0 \\
\hline
\end{tabular}

Among the general characteristics of the study subjects, based on gender distribution, there were more women than men respondents or $353(69.9 \%)$ women and $152(30.1 \%)$ men. Based on their college courses, $239(47.3 \%)$ are taking up college of the health science, $233(46.1 \%)$ for college of health industry, and 33 (6.5\%) for college of nursing. Based on their major, most of the respondents were from the Department of Food Industry and Food and Rural Affairs while the least respondents were from the Department of Food and Nutrition, or 52 and 12 students, respectively.

\subsection{Measuring instrument}

This study used the tool Hong (2006) developed in his study to secure validity and reliability in measuring a college student's reading attitude and strategy and. The reading attitude assessment consisted of nine questions, including the value of reading, reading behavior, other people's judgment of their reading ability, their judgment of their reading power, and the use of various reference books [9]. The reading strategy assessment consisted of a total of 19 questions with three subfactors: 3 questions on reading strategy before reading, 6 questions on reading strategy during reading, and 9 subfactors on reading strategy after reading. The measure of the tool is a four-point Likert scale indication "very much" with four points and "not at all" with one point.

The Motivations for Reading Questionnaire (MRQ) developed by Wigfield and Guthrie (2004) was used to measure the motivations for reading in university students [10]. The motivations for reading consisted of eight variables: curiosity, immersion, challenge, recognition, sexuality, sociality, competition, and conformity. This study also used the tools, the tools developed by Wang and Guthrie (2004) which before consisted of 39 questions in total, using seven variables of curiosity, immersion, challenge, recognition, sociality, competition, and conformity, excluding the grades unfit for the subject of college students [10]. Among the seven variables, the inner motives comprise three sub-variables-seven questions of curiosity, five questions of immersion, and five questions of challenge - and the external motives consist of four sub-variables - five questions of recognition, six questions of social nature, six questions of competition, and three questions of conformity. The tool is a four-point Likert scale indicating "very much" for four points and "not at all" for one point. The configuration by sub-parameters of reading motivation used in this study and the confidence factor, Cronbach's $\alpha$, are shown in Table 2 .

Table 2 :Statement composition and reliability factor of measurement tools

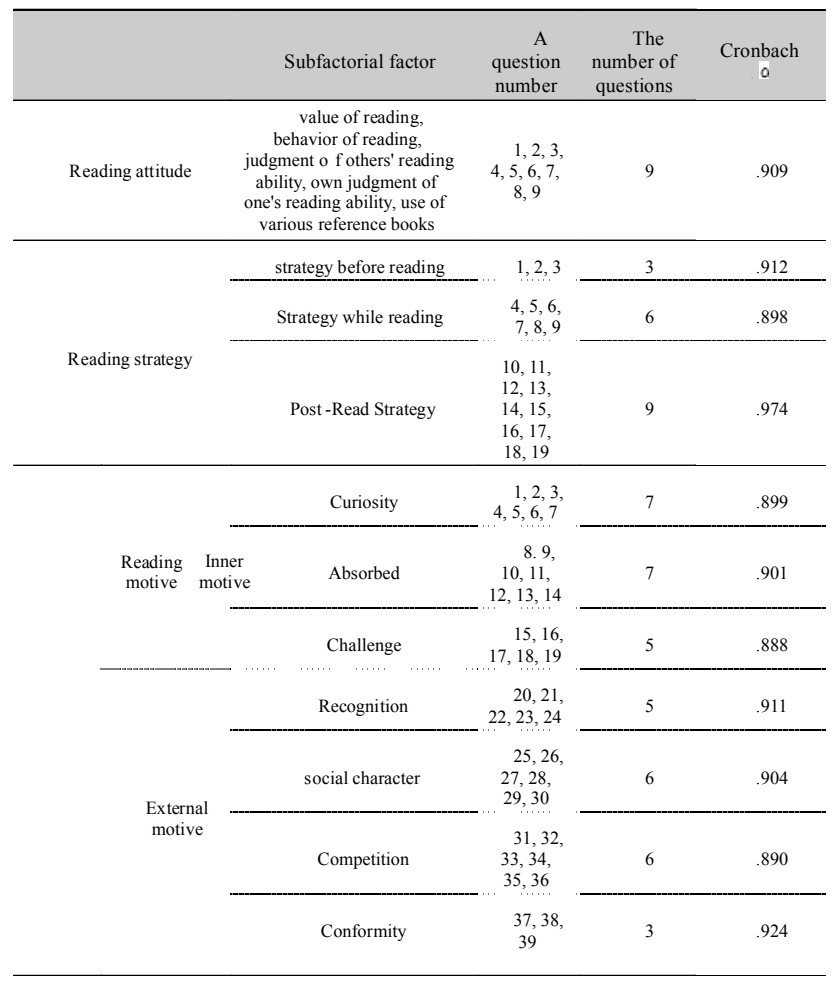

\subsection{Data analysis}

This research used PASW Statistics 18.0 and AMOS 18.0 programs to analyze the data gathered. First, frequency analysis and technical statistics analysis were conducted to examine the average and standard deviation of the demographic and social factors of those surveyed. The correlations were determined to examine the relationship between the measurement variables, and multiple coherence, which confirmed the high interrelationships among the independent variables. In addition, the goodnessof-fit index presented in college students' reading attitude, reading strategy, and model verification using a structure model between reading drivers showed how well the theoretical model described the 
data compared to the absolute equivalence index (RMSEA) and the worst independent model (NFI, IFI, TLI, CF)[11]. To evaluate a research model properly, it is necessary to select a model that is well matched to the data without being affected by the size of the sample, while at the same time being concise.

To solve this research problem, for subfactors of university students' reading attitudes, reading strategies, and reading drivers were modeled using structural equation models as a group index. By combining several questions, the grouping index has the advantage of increasing the range of the index scores, making it more likely to achieve normal distribution and become a more reliable indicator. It also has the advantage of reducing the estimated error by reducing the number of parameters that are estimated to less than that from the use of individual questions [12, 13]. The Maximum Likelihood Estimate (ML) is adopted for the parametric estimates.

\section{Result analysis}

3.1. Correlation with technical statistics on reading attitude, strategy, and motivation

Descriptive statistics were calculated based on the average and standard deviation of the measurement variables in this study, and correlation analysis was conducted to examine the relationship between the measurement variables. The analysis result is as follows.

Table 3 : Descriptive statistics on reading attitude, strategy, and motivation

\begin{tabular}{|c|c|c|c|c|c|c|}
\hline & & & $\begin{array}{c}\text { Minimum } \\
\text { Value }\end{array}$ & $\begin{array}{c}\text { Maximum } \\
\text { Value }\end{array}$ & M & SD \\
\hline & \multicolumn{2}{|c|}{ Reading Attitude } & 1.00 & 5.00 & 2.3274 & .49871 \\
\hline \multicolumn{3}{|c|}{ strategy before reading } & 1.00 & 4.00 & 2.4620 & .64305 \\
\hline \multirow{3}{*}{ Strategy } & \multicolumn{2}{|c|}{ Strategy while reading } & 1.00 & 4.00 & 2.6286 & .52501 \\
\hline & \multicolumn{2}{|c|}{ PostRead Strategy } & 1.00 & 4.00 & 2.2809 & .53840 \\
\hline & \multicolumn{2}{|r|}{ Total } & 1.00 & 4.00 & 2.4572 & .48296 \\
\hline \multirow{8}{*}{ Motivation } & \multirow{3}{*}{ Inner motive } & Curiosity & 1.00 & 4.00 & 2.6504 & .46817 \\
\hline & & Absorbed & 1.00 & 4.00 & 2.7253 & .51421 \\
\hline & & Challenge & 1.00 & 4.00 & 2.3552 & .58930 \\
\hline & \multirow{4}{*}{$\begin{array}{l}\text { External } \\
\text { motive }\end{array}$} & Recognition & 1.00 & 4.00 & 2.4519 & .71253 \\
\hline & & social character & 1.00 & 4.00 & 2.1736 & .61238 \\
\hline & & Competition & 1.00 & 4.00 & 1.9462 & .63640 \\
\hline & & Conformity & 1.00 & 4.00 & 2.1881 & .69137 \\
\hline & & Total & 1.00 & 3.92 & 2.3833 & .41343 \\
\hline
\end{tabular}

The results of the descriptive statistics analysis showed that the average reading attitude was 2.32 points, the average reading strategy was 2.45 points, and the motivation for reading was 2.38 points. Table 4 shows the results of the correlation.

Table 4 : Correlation Analysis Results

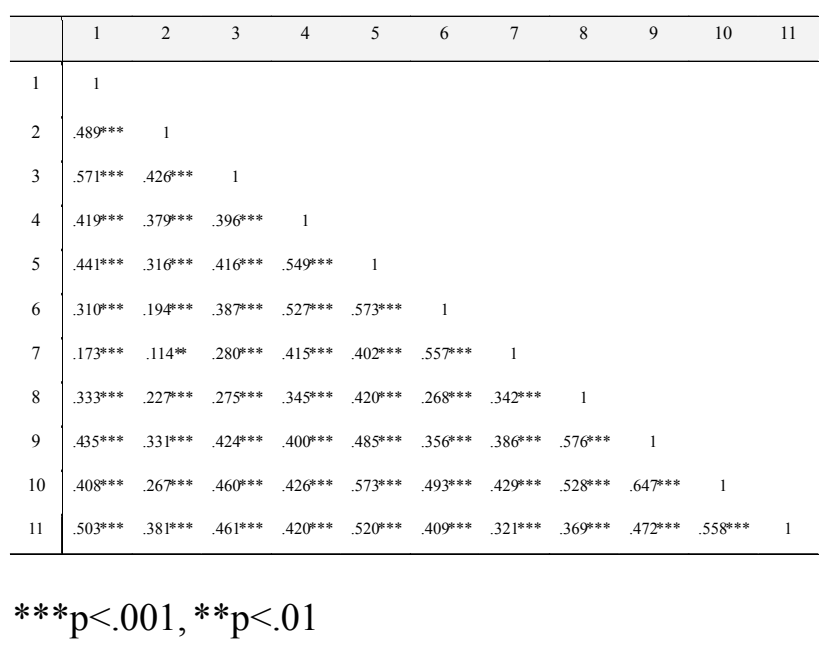

1. Curiosity, 2. Absorbed, 3. Challenge, 4. Recognition, 5. Social character, 6. Competition, 7. Conformity, 8. Strategy before reading, 9. Strategy while reading, 10. Post-Read Strategy, 11. Reading Attitude

As a result of the correlation, the relationship between reading attitude, reading strategy, and reading motivation variables all showed static correlation. The multicollinearity, which means high interrelationship between independent variables, was identified.

3.2. The structural relationship between reading attitude and motivation influencing reading strategies

A structural model was established based on prior research to analyze the structural relationship between university students' reading attitudes and motivations and the influence on their reading strategies. To verify this, a bundle indicator [14] was used as an average value by linking the measurement variables to reduce the estimated error caused by a large number of measurement questions depending on each potential factor and to ensure multivariate normality. The initial research model is shown in Fig. 1, and the results of the suitability analysis are shown in Table 5.

The suitability test for the structural model rejected the null hypothesis that the model would be consistent 


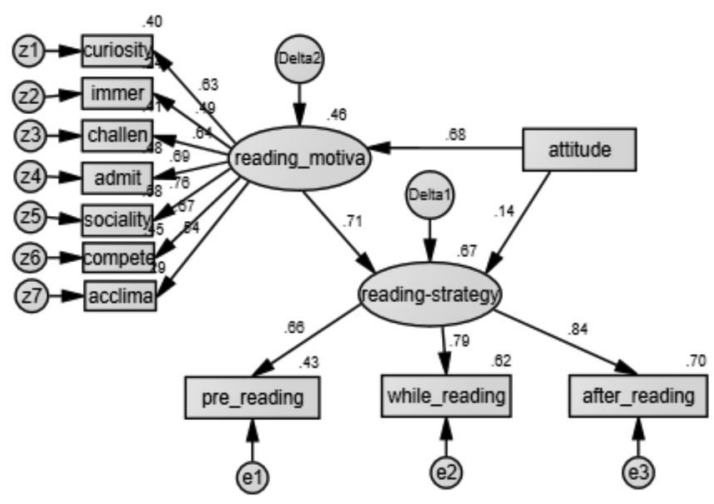

Fig. 1 : Early research model

Table 5 : An analysis of the suitability of early research models

\begin{tabular}{llllllll}
\hline & $\chi^{2}(\mathrm{p})$ & df & RMSEA & NFI & IFI & TLI & CFI \\
\cline { 1 - 6 } $\begin{array}{l}\text { Research } \\
\text { model }\end{array}$ & $328.855(.000)$ & 42 & .116 & .899 & .898 & .900 & .887 \\
\cline { 2 - 2 } $\begin{array}{l}\text { Acceptance } \\
\text { criteria }\end{array}$ & $\mathrm{p}>.05$ & & $<.10$ & $>.9$ & $>.9$ & $>.9$ & $>.9$ \\
\hline
\end{tabular}

with the data at a significance level of .05 . The RMSEA value of .166 in this study is not a good fit, as claimed by Steiger (1990), who evaluated it as a good fit if it is .05 or less and the best fit if it is .01 or less. Therefore, some modifications were made to the research model by reflecting the theory for good practice to explore models that could better reflect the characteristics of the data. To modify the research model, the correction index 'Modification indices' was checked, where a larger correction index indicates that the item needs modification. Therefore, it was necessary to examine the appropriateness of the model by sequentially modifying the items shown in the 'Modification indices.'

An analysis of the correction index shows that the correction that sets the correlations between the error terms "z1" and "z2", "z1" and "z3", and "z6" and "z7" of reading motivation to increase the degree of conformance. The implication of this is that the subfactors of reading motivations, curiosity, immersion, and challenge all fall within the internal motivations of reading motivations, without measuring each unique content, which can be said to be meaningful in the correlations between the pairs of error terms.

Therefore, the correction model was designed and reanalyzed by setting the correlations between the error terms ' $z 1$ ' and ' $z 2$ ', 'z1' and 'z3', and 'z6' and ' $z 7$ ' of the reading motivation according to the result of the correction index analysis. The most suitable model based on these results is given in Fig. 2, which shows the direct and indirect effects between variables. The conformity results for this model are given in Table 6 .

Table 6 shows that the value of the index fit

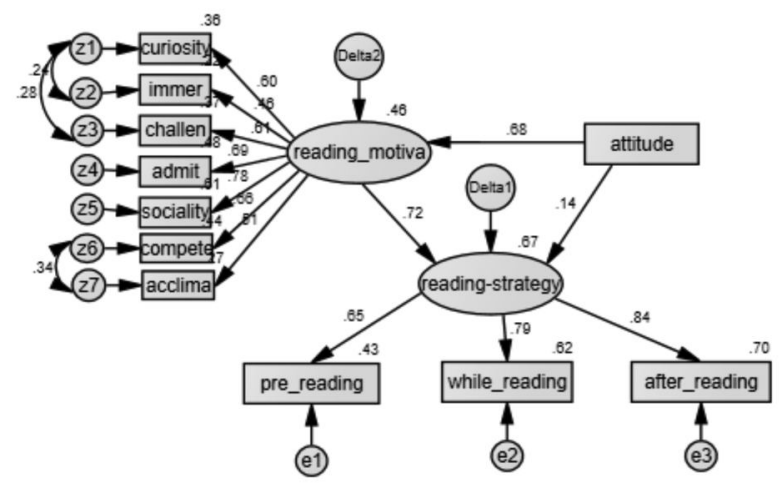

Fig. 2 Modification model of university student's reading attitude, motivation, and the relationship of reading strategy (Standardization factor)

Table 6 : Conformity of modification model

\begin{tabular}{llllllll}
\hline & $\chi^{2}(\mathrm{p})$ & $\mathrm{df}$ & RMSEA & NFI & IFI & TLI & CFI \\
\hline Research model & $328.855(.000)$ & 42 & .116 & .899 & .898 & .900 & .887 \\
\hline Modification model & $194.401(.000)$ & 39 & .079 & .919 & .934 & .906 & .934 \\
\hline Acceptance criteria & $\mathrm{p}>.05$ & & $<.08$ & $>.9$ & $>.9$ & $>.9$ & $>.9$ \\
\hline
\end{tabular}

indicator is 194.401 , the significance probability is .49 , and the close fit indicator, RMSEA, of .079 can be evaluated as indicating a good revised model. The relative convergence indices NFI, IFI, TLI, and CFII all conform to acceptance criteria and can be evaluated as indicating a good model. The effectiveness factor of the revised model for reading strategies is shown in Table 7.

Table 7 : Coefficient of the effect of modified model

\begin{tabular}{lllllll}
\hline \multicolumn{2}{l}{ Path of Modification Model } & Estimate & S.E. & C.R. & $\mathrm{p}$ \\
\hline Motivation & $\leftarrow$ & $\begin{array}{l}\text { Reading } \\
\text { Attitude }\end{array}$ & .677 & .042 & $14.95^{* * *}$ & .000 \\
Strategy & $\leftarrow$ & $\begin{array}{l}\text { Motivation } \\
\text { Reading }\end{array}$ & .714 & 2.496 & $2.16^{*}$ & .023 \\
Strategy & $\leftarrow$ & $\begin{array}{l}\text { Attitude } \\
\text { Atur }\end{array}$ & 1.00 & & & \\
\hline$* * * p<.001$ & & & & & &
\end{tabular}

From the C.R. value, as shown in Table 7, all path coefficients between potential variables were significant $(p<.001)$. As shown in Table 7 , the estimated path coefficients and path coefficients among the variables set in the revision model were of statistically significant probability levels in 'Reading attitude $\rightarrow$ Motivation', 'Motivation $\rightarrow$ Strategy', and 'Reading attitude $\rightarrow$ Strategy'. 
Also, when the motivation for reading was used as a parameter, the direct and indirect effects of university students' reading attitude on strategy were examined. The methods Sobel Verification, Aroian Verification, Goodman Verification, and Bootstrapping are used for testing the significance of indirect effects. In this study, Bootstrapping was adopted for estimating the sample distribution of parametric estimates and treating arbitrary samples of data as the whole of the population. The method used for calculating the significance of indirect effects was the Bias-Corrected Percentile method with a high degree of bias. In Table 8, an analysis based on the bootstrapping method is presented.

Table 8. Direct and indirect effects of the measurement model on the modified model (standardization factor)

Table 8 : Direct and indirect effects of the measurement model on the modified model (standardization factor)

\begin{tabular}{|c|c|c|c|c|c|}
\hline Path type & Path Engagen & & $\begin{array}{l}\text { ect } \\
\text { ects }\end{array}$ & $\begin{array}{l}\text { indirect } \\
\text { effect } \\
\text { (reading } \\
\text { motive) }\end{array}$ & $\begin{array}{l}\text { Full } \\
\text { effect }\end{array}$ \\
\hline $\begin{array}{l}\text { Independent variable } \rightarrow \\
\text { Parameter }\end{array}$ & $\begin{array}{l}\text { Reading } \\
\text { Attitude }\end{array}$ & $\rightarrow \begin{array}{l}\text { Motivati } \\
\text { on }\end{array}$ & $.676^{* * *}$ & - & $.676^{* * *}$ \\
\hline $\begin{array}{l}\text { Independent varia ble } \rightarrow \\
\text { Dependent variable }\end{array}$ & $\begin{array}{l}\text { Reading } \\
\text { Attitude }\end{array}$ & $\rightarrow$ Strategy & $.139 * *$ & $.487^{* * *}$ & $.626^{* * *}$ \\
\hline $\begin{array}{l}\text { Parameter } \rightarrow \text { Dependent } \\
\text { variable }\end{array}$ & Motivation & $\rightarrow$ Strategy & $.721^{* * *}$ & - & $.721^{* * *}$ \\
\hline
\end{tabular}

As shown in Table 8, first, college students' reading attitudes motivated by reading $(.676, \mathrm{p}<.001)$ showed a total effect. Second, the motivation for reading showed a total effect on reading strategy $(.721$, $\mathrm{p}<.001)$. Third, college students' reading attitude showed indirect effects on strategy with motivation $(.487, \mathrm{p}<.01)$, and total effect $(.626, \mathrm{p}<.001)$. It was found that the motivation for reading is directly more influential on reading strategy than the attitude of reading students who use motivation as a medium. Therefore, it is necessary to first raise the motivation for reading, although reading habits are also important, to enhance the reading strategy of university students.

\section{Conclusion}

In this study, we analyzed the structural relationship between reading attitudes and motivations that affect a college student's reading strategy. In particular, the structural relationship between reading attitude and reading-attitudeaffected strategy was analyzed through the medium of motivation. The study results are summarized as follows.
The reading strategy of university students shows that the motivation of reading is directly more influential on the reading strategy than the attitude of university students who use reading motivation as a medium.

These findings are supported by the studies conducted by Wigfield and Guthrie in 1997 and 2000, which showed that students' high motivation to read increases the volume and scope of reading, and that they exercise a reading strategy $[15,16]$. It can be understood in the same context of the study of Ryu Sukyeong (2020), which shows that differentiated reading strategies depend on the motivation of reading, whether the purpose is to gain new knowledge or to reaffirm what has been learned and to prepare for a test [17]. Also in his study, reading strategies such as adjusting reading speed, refinement, reasoning, and critical reading were appropriately utilized according to the motivation of college students [17].

Also, a teaching strategy to promote reading motivation was introduced to give learners a choice of books [18]. When presenting options, a strategy of presenting them in an informative way rather than in a controlled manner is also necessary. Providing a choice in an informational manner allows you to choose to respond to personal preferences and goal but provide the option in a controlled manner makes you choose to manipulate and control the opponent. In other words, bilaterally providing a choice is like pressuring and forcing learners to make a choice [19]. Meanwhile, receiving too many options can also be overwhelming and de-synchronous [20]. Therefore, to select and read books or to participate in a variety of reading programs, to organize options by reflecting learners' preference for reading and the value of reading they pursue, and to choose reading activities. We should make sure that it is not caused by the pressure around us, but what we want and value.

The study of reading motivations should move from diagnosing learners' reading motivations to developing educational measures to form their reading motivations. This requires a critical review of whether the existing motivational teaching strategies at school sites are appropriate for motivating learners to read, and a theoretical discussion is needed to support them.

Therefore, with the help of this study, it is necessary to promote awareness of the importance of university 
students' reading motives. Further research is required for the development of various programs to improve and support the reading environment in universities. Empirical research on the motives of reading by university students will be needed, and a study should be conducted to provide basic data on reading strategies and attitudes. With this, we can foster creative talent, with sound personalities and critical thinking skills, to lead the era of the Fourth Industrial Revolution [21].

\section{References}

[1] Park, S. S. "The Review of Teaching Reading in College." Journal of reading research, 12 (2004): 31-48.

[2] Chall, J. S. Stages of reading development. Fort Worth, TX: Harcourt Brace, 1996.

[3] Wood, F. B. Becoming a reader. Needham Heights, MA: Allyn \& Bacon, 1992.

[4] Korean Reading Society. 21st Century Society and Reading Guidance, Seoul: Park, Lee Jung, 2003.

[5] Kim, H. N. The Relationship between Family Literacy, Reading Attitude and Reading Comprehension of Elementary School Students. Master's Thesis. Catholic University, 2004.

[6] Lewis, R. \& Teale, W. H. "Another look at secondary school students attitudes toward reading." Journal of Reading Behavior, 12 (1980): 187-201.

[7] Logan, S., Medford, E., \& Hughes, N. "The importance of intrinsic motivation for high and low ability readers' reading comprehension performance." Learning and Individual Differences, 21 (2011): 124-128.

[8] McGeown, S. P. Johnston, R., Walker, J., Howason, K., Stockburn, A., \& Dufton, P. "The relationship between young children's reading attitudes, confidence and attainment." Educational Research, 57 (2015): 389-402.

[9] Hong, H. S. A Study on the Reading Attitude and the Use of Strategy in College Students. Master's Thesis, Graduate School of Education, Catholic University, (2006).
[10] Wigfield, A., Guthrie, J. T., Tonks, S., \& Perencevich, K. C. "Children's motivation for reading: Domain specificity and instructional influences." Journal of Educational Psychology, 97 (2004): 299-399.

[11] Hong, S. H. "Basis for Selection Criteria for Goodness-of-Fit Index of Structural Equation Model." Korean Journal of Psychology: Clinical, 19.1(2000): 161-177.

[12] Kishton, J.M., \& Widaman, K.F. "Unidimensional versus domain representative parceling of questionnaire items: An empirical example." Educational and Psychological Measurement, 54.3(1994): 757-765.

[13] Landis, R. S., Beal, D. J., \& Tesluk, P. E. “A comparison of approaches to forming composite measures in structural equation models." Organizational Research Methods, 3(2000): 186-207.

[14] Bandalos, D. L. "The effects of item parceling on goodness-of-fit and parameter estimate bias in structural equation modeling." Structural Equation Modeling, 9.1(2002): 78-102.

[15] Wigfield, A. \& Guthrie, J. T. "Relations of children's motivation for reading to the amount and breadth of their reading." Journal of Educational Psychology, 89(1997): 420-432.

[16] Guthrie, J. T. \& Wigfield, A. "Engagement and motivation in reading." Handbook of reading research, 3(2000): 403-420.

[17] Ryu, Su. kyeong. "Theoretical Exploration of Intrinsic Reading Motivational Teaching Strategies." Reading research, 54(2020): 39-64.

[18] Wutz, J. A. \& Wedwick, L. "BOOKMATCH: Scaffolding book selection for independent reading." The Reading Teacher, 59.1(2005): 1632.

[19] Moller, A. C., Deci, E. L., \& Ryan, R. M. "Choice and ego-depletion: The moderating role of autonomy." Personality and Social Psychology Nulletin, 36(2006): 754-767.

[20] Iyengar, S. S. \& Kamenicab, E. "Choice 
proliferation, simplicity seeking, and asset allocation." Journal of Public Economics, 94.7, 8(2010): 530-539.

[21] Kim, E. J. "Structural Relationship between
Reading Attitudes, Reading Motives and Reading Strategies of University Students." Journal of humanities research and methodology, 1.1(2020): 27-32. 